East African Medical Journal Vol. 84 No. 11 November 2007

CLEAN INTERMITENT CATHETERISATION IN THE MANAGEMENT OF URETHRAL STRICTURES

P.M. Ngugi, MBChB, MMed (Surg), Senior Lecturer, Department of Surgery, College of Health Sciences, University of Nairobi, P.O. Box 19676-00202, Nairobi, Kenya and A. Kassim, MBChB, MMed (Surg), District Surgeon, Kilifi District, Kilifi, Kenya

Request for reprints to: Dr. P.M. Ngugi, Department of Surgery, College of Health Sciences, University of Nairobi, P.O. Box 19676-00202, Nairobi, Kenya

\title{
CLEAN INTERMITENT CATHETERISATION IN THE MANAGEMENT OF URETHRAL STRICTURES
}

\author{
P.M. NGUGI and A. KASSIM
}

\begin{abstract}
Objective: To compare clean intermittent self-catheterisation and urethral dilatation with sounds in the management of recurrent urethral strictures.

Design: A prospective randomised control trial between repeated urethral dilatation with sounds and use of clean intermittent self-catheterisation in the management of recurrent urethral strictures. Setting: Kenyatta National Hospital, urology clinics.

Subjects: Forty nine patients with recurrent urethral strictures were randomised between clean intermittent catheterisation (CISC) and urethral dilatation with sounds.

Results: The urinary flow rates were better in patients on the CISC arm compared to the dilatation arm. Seventy three percent of patients having clutton sounds dilatation developed urinary tract infections compared to $25 \%$ of those on CISC. The patients in the CISC arm had a uniformly higher quality of life score than those having sounds dilatation of the urethra.

Conclusion: Clean intermittent self-catheterisation is an effective and safe way of managing recurrent urethral strictures. It is a better method than repeated clutton sounds dilatation.
\end{abstract}

\section{INTRODUCTION}

Urethral strictures are a major cause of morbidity and have been managed mainly by way of repeated clutton sounds dilatation. CISC is easy to teach and is associated with very few complications (1). CISC was first described by Lapiides in 1972. Studies have shown that CISC can prevent recurrence of strictures but stoppage of the practice leads to recurrence of the stricture (2-4).

The earliest use of urethral dilatation for the treatment of urethral strictures is found in Ayurveda a Hindu treatise of medicine from the 6th century $\mathrm{BC}$ where Sursuta advocates treatment by gradual dilatation using dilators made of wood (5). Harris et al (3) addressed the duration of CISC required to cause stricture stabilisation. They showed that CISC is safe and effective in preventing stricture recurrence in the long term. The recurrence of stricture was much lower when CISC was continued for more than 12 months than when it was stopped at 12 months. Robertson (1) treated 65 patients with CISC for a period of three years. The study showed a marked reduction on the number of repeat operations performed on these patients. The investigators felt that method offers the possibility of long-term cure and should be offered to such patients, thus reducing the number of patients that require urethroplasty (1).

Uroflowmetry is useful in the follow-up of patients with urethral stricture and can be used to assess the course of a urethral stricture (6).

\section{MATERIALS AND METHODS}

A prospective study was conducted after obtaining institutional review board approval at the Kenyatta National Hospital. A randomised clinical control 
trial was conducted between October 1998 and June 1999.

Patients attending the Kenyatta National Hospital with recurrent urethral strictures for urethral dilatation were entered into the study after informed consent. Randomisation was then done by use of a sequence of random numbers generated by a computer. The patients were randomised to either continue with urethral dilatation as was being practiced before, or to clean intermittent selfcatheterisation. Patients on the self-catheterising arm were shown how to do the procedure and then instructed to self-catheterise twice a day. The catheterisation was done using a Nelaton catheter size 14. After the procedure the catheter was washed with soap and water and then immersed in an antiseptic solution, e.g. chorhexidine, until it was next needed. The patients were then asked to change the catheters every two to four weeks. The patients on the dilatation arm had urethral sounds dilatation at one month, three months and six months.

Urinary flow rates were determined at recruitment and then at one month three months and six months for both groups. This was done using a Uroflowmetry machine (urodyn100).

At each visit the patients were asked to give their own view of their mode of treatment and how it affected their lives. A quality of life score of the way the patient felt was done using a scoring system that scored four for terrible, three for unhappy, two for indifferent, one for pleased and zero for delighted.

All the data were entered into an IBM computer utilising Statistical Package for Social Sciences (SPSS). Frequency distribution was done and statistical differences checked with chi-square test. EPI INFO was used to calculate p-value using Fisher's exact test where the numbers were too small or the SPSS Programme where they were not. $P$-value would be significant when the p-value was less than or equal to 0.05

Permission to carry out the study was sought and obtained from the ethical and research committee.

\section{RESULTS}

A total of 49 patients were recruited into the study, 27 of them in the CISC group and 22 in the control group (Table 1).

The age range in the CISC group was $15-75$ years while that in the control group was 15-66 years.
The commonest cause of stricture post-infective urethritis (51\%) (Table 2).

Table 1

Distribution of patients in the study groups by age

\begin{tabular}{|c|c|c|c|c|c|}
\hline \multirow[t]{2}{*}{$\begin{array}{l}\text { Age group } \\
\text { (years) }\end{array}$} & GPA (CISC) & \multicolumn{2}{|c|}{$\begin{array}{c}\text { GPB } \\
\text { (Dilatation) }\end{array}$} & \multicolumn{2}{|c|}{ Total } \\
\hline & No. $(\%)$ & No. & $(\%)$ & No. & $(\%)$ \\
\hline $15-29$ & $\begin{array}{ll}9 & 69.2\end{array}$ & 4 & 30.8 & 13 & 26.5 \\
\hline $30-44$ & $\begin{array}{ll}7 & 38.9\end{array}$ & 11 & 61.1 & 18 & 36.7 \\
\hline $45-59$ & $\begin{array}{ll}7 & 58.3\end{array}$ & 5 & 41.7 & 12 & 24.5 \\
\hline$\geq 60$ & $\begin{array}{ll}4 & 66.7\end{array}$ & 2 & 33.3 & 6 & 12.3 \\
\hline Total & 2755.1 & 22 & 44.9 & 49 & 100 \\
\hline Mean \pm SD & $40.7 \pm 17.98$ & $39.96 \pm$ & 13.24 & $39.72 \pm$ & 17.98 \\
\hline Range & $15-75$ & 15 & & $15-7$ & 75 \\
\hline
\end{tabular}

Table 2

Aetiology distribution between CISC and dilatation

\begin{tabular}{lcccccc}
\hline $\begin{array}{l}\text { Age group } \\
\text { (years) }\end{array}$ & GPA (CISC) & \multicolumn{2}{c}{ GPB } & & Total \\
& No. (\%) & No. (\%) & No. (\%) \\
\hline Urethritis & 13 & 48.1 & 12 & 54.5 & 21 & 51 \\
Trauma & 10 & 37.0 & 6 & 27.3 & 16 & 32.7 \\
latrogenic & 8 & 29.6 & 13 & 13.6 & 11 & 2.4 \\
\hline
\end{tabular}

The mean flow rates at recruitment were similar with that for group A being $11.71 \pm 10.88 \mathrm{mls}$ per second while group B was $9.92 \pm 10.71 \mathrm{mls}$ per second. This changed to $18.9 \pm 9.89$ and $8.17 \pm 3.93$ mls per second respectively at one month, $18.90 \pm$ 9.75 and $5.39 \pm 3.38$ at three months, and $18.66 \pm$ 11.48 and $7.72 \pm 2.65$ at six months respectively at six months for groups A and B.

There was no difference between the flow rates for groups A and B at recruitment with a p-value of 0.79565 , but at one month this was significant with a p-value of 0.00022 . At three months the difference was maintained with a p-value of 0.00015 and at six months with a p-value of 0.00165 .

The results show that there was a steady increase in the flow rates in group $A$ at one month, three months and at 6 months. The flow rates for group $B$ did not improve significantly in the study period (Table 3).

In the subjective quality of life assessment we divided the results into those who were happy and those who were not. 
Table 3

Quality of life at one response

\begin{tabular}{lcccccc}
\hline Study group & Happy & \multicolumn{2}{c}{ Unhappy } & \multicolumn{2}{c}{ Total } \\
& No. $(\%)$ & No. & $(\%)$ & No. & $(\%)$ \\
\hline A & 25 & 100 & 0 & 0 & 25 & 53.2 \\
B & 16 & 72.7 & 6 & 27 & 22 & 46.8 \\
\hline Total & 41 & 87.2 & 6 & 12.8 & 47 & 100 \\
\hline
\end{tabular}

Table 4

Quality of life response at three months

\begin{tabular}{lccccccc}
\hline Study group & \multicolumn{2}{c}{ Happy } & \multicolumn{2}{c}{ Unhappy } & \multicolumn{2}{c}{ Total } \\
& No. & (\%) & No. & $(\%)$ & \multicolumn{2}{c}{ No. } & $(\%)$ \\
\hline A & 22 & 88 & 3 & 12 & & 25 & 59.5 \\
B & 2 & 11.8 & 15 & 88.2 & & 17 & 40.5 \\
\hline Total & 24 & 57.1 & 18 & 42.9 & & 42 & 100 \\
\hline
\end{tabular}

Table 5

Quality of life response at six months

\begin{tabular}{|c|c|c|c|}
\hline Study group & $\begin{array}{l}\text { Happy } \\
\text { No. (\%) }\end{array}$ & $\begin{array}{l}\text { Unhappy } \\
\text { No. }(\%)\end{array}$ & $\begin{array}{c}\text { Total } \\
\text { No. }(\%)\end{array}$ \\
\hline A & 1785 & 15 & 2057.1 \\
\hline B & 320 & 80 & $15 \quad 42.9$ \\
\hline Total & 2057.1 & $15 \quad 42.9$ & $35 \quad 100$ \\
\hline
\end{tabular}

There was a significant difference between the two groups in those who were and those not happy with a p-value of 0.01 at one month, 0 at 3 months and 0.12 at 6 months (Table 5).

There was no significant difference in the infection rates between the two groups at recruitment but there was a higher rate of infection in the dilatation group at three months and at six months although this was not statistically significant.

\section{DISCUSSION}

A total of 49 patients were recruited into the study. Thirteen and 10 of them were lost to follow-up at three months and six months respectively. The majority of the patients were between 15 and 44 years of age. This compares well with the work of Adwok in 1986 which showed strictures to be commonest between 30 and 40 years of age while Ahmed and Kalayi of Nigeria found the commonest incidence to be between 21 and 40 years of age $(7,8)$.

Urinary flow rates were the main outcome measure of the study. Urinary low rates in a normal individual vary according to age and gender. Young men and women have high flow rates. The normal flow rate for a normal adult man is $15 \mathrm{mls}$ per second. The results show that clean intermittent catheterisation led to a rise in flow rates at one and three months which was still maintained at six months. On the other hand patients who had repeated dilatation only had maintained low flow rates during the study period in spite of the repeated dilatation with sounds.

Patients on repeated urethral dilatations had a higher rate of infections probably indicating that repeated dilatation did not allow for adequate voiding and therefore stagnation with consequent infection.

The quality of life assessment showed that the patients that were doing CISC reported a better quality of life than those who repeated dilatation with sounds.

In conclusion, clean intermittent self catheterisation is an effective way of treating recurrent urethral strictures and is superior to repeated dilatations with sounds.

\section{REFERENCES}

1. Robertson G.S., Everit N., et al. Treatment of recurrent urethral strictures with clean intermittent selfcatheterisation. Brit. J. Urol. 1991; 68: 89-92.

2. Lawrence W.T., Macdonald R.P., et al. New treatment of urethral strictures. Lancet. 1988; 2: 572.

3. Tammela T.L., Permi T., et al. Intermittent selfcatheterisation after urethrotomy for recurrent urethral strictures. Ann. Chir. Gynaecol. Suppl. (Finland). 1993; 206: 80-83.

4. Harris D.R., Beckingham I.J., et al. Long-term results of intermittent low friction self catheterisation in patients with recurrent urethral strictures. Brit. J. Urol. 1994; 74: 790-792.

5. Singh M., Husain I., et al. Textbook of tropical urology and renal disease. Vol. 1 , page 325 .

6. Huari. D. The value of uroflowmetry in the diagnosis of urethral strictures. Urologe. 1978; 17: 171-176.

7. Adwok J.A Urethral strictures at the Kenyatta National Hospital. East Afr. Med. J. 1986; 63: 175-181.

8. Ahmed A. and Kalayi G.D. Urethral strictures at Ahmadu Bello University Teaching Hospital, Zaria. East Afr. Med. J. 1988; 75: 582-585.

9. Haylen B.T., Ashby D. et al. Maximum and average urine flow rates in normal male and female population. The Liverpool normograms. Brit. J. Urol. 1989; 64: 30-38. 
East African Medical Journal Vol. 84 No. 11 November 2007

OBSTETRIC FISTULA IN RURAL ETHIOPIA

M. Muleta, MD, (Obst \& Gynae), MPH, Addis Ababa Fistula Hospital, P.O. Box 3609, Addis Ababa, Ethiopia, M. Fantahun, MD, MPH, Department of Community Health, Addis Ababa University, P.O.Box 24762-1000, Addis Ababa, Ethiopia, B. Tafesse, MD, (Obst \& Gynae), MPH, E.C. Hamlin, AC, MBBS, FRCS, FRCOG, FRANZCDHG, R.C. Kennedy, SRN, SCM and R.C. Kennedy, SRN, SCM, Addis Ababa Fistula Hospital, P.O. Box 3609, Addis Ababa, Ethiopia

Request for reprints to: Dr. M. Muleta, Addis Ababa Fistula Hospital, P.O. Box 3609, Addis Ababa, Ethiopia

\title{
OBSTETRIC FISTULA IN RURAL ETHIOPIA
}

\author{
M. MULETA, M. FANTAHUN, B. TAFESSE, E.C. HAMLIN and R.C. KENNEDY
}

\begin{abstract}
Objectives: To determine the prevalence of obstetric fistula in rural Ethiopia and identify the circumstances and barriers to care that enhance development of obstetric fistula and its health and social consequences.

Design: A cross-sectional study.

Setting: The study was conducted in seven out of eleven administrative regions of Ethiopia by visiting randomly selected houses in rural areas and identifying women who have or had obstetric fistula and interviewing them.

Results: A total of 19,153 houses were visited. Untreated fistula prevalence was about 1.5 per 1000 amounting to approximately 26,819 women. Most of the patients were young women who delivered for the first time. Marriage took place early in life mostly through family arrangements or abduction. The median number of days in labour was three to eight.

Conclusion: Promotive measures such as increasing age at marriage, and identification and treatment of patients should be intensified. There is a great need in improving accessibility and affordability of basic and emergency obstetric services for rural communities. Curving the situation in the long run requires dealing with the problem of poverty and improvement in the status of women.
\end{abstract}

\section{INTRODUCTION}

Obstetric fistula is one of the major complications of childbirth, causing misery to many women of developing countries. Although the causes of obstetric fistula are generally known, the extent of the problem, and the factors associated with its development are not clearly documented in Ethiopia and many developing countries. On the other hand, development of a national or sub-national strategy for the prevention and treatment of obstetric fistula requires information on prevalence and incidence of the disease and identifications of specific local determinants (1).

The few available hospital based data indicate obstetric fistula is still a common health problem in Ethiopia and other developing countries (2-5). Maternal mortality ratio of Ethiopia is one of the highest in the world, $871 / 100,000$ live births (6). Additionally, it is estimated that more than 500,000 Ethiopian women and girls suffer from disabilities caused by complications during pregnancy and child birth each year (7).

The Addis Ababa Fistula Hospital (AAFH) has been repairing obstetric fistulae for more than three decades. However, the number of fistula patients coming to the hospital does not appear to decrease indicating the need to develop appropriate intervention, the first step of which is measuring the extent of the problem in the community.

Thus, the objectives of this study were to determine the prevalence of obstetric fistula in rural 
Ethiopia and identify the circumstances and barriers to care that affect development of obstetric fistula and its health and social consequences.

\section{MATERIALS AND METHODS}

A cross-sectional study was conducted in seven out of eleven administrative regions of the country and included both quantitative and qualitative components. House to house survey was undertaken in a sample of kebeles (smallest administrative units in Ethiopia) or villages to collect information of any one who is having and/or had obstetric fistula in the past. Multistage sampling (five stages) was used to select women who have or had obstetric fistula following the administrative structure of the country which consists of regions, zones, districts, kebeles and villages (Figure 1). While the three biggest regions were represented by two randomly selected zones, the others were represented by one zone. From each zone a district was randomly selected. Subsequently kebeles or villages were randomly selected until the required sample size was achieved for each region. All household members in the selected kebeles or villages were enumerated and women in the selected kebeles or village(s) who have (or had) a problem of bladder and/or bowel control, now or in the past were interviewed. The study was conducted between January 2005 and June 2005.

Figure 1

Schematic presentation of the sampling procedure to select fistula patients in Ethiopia

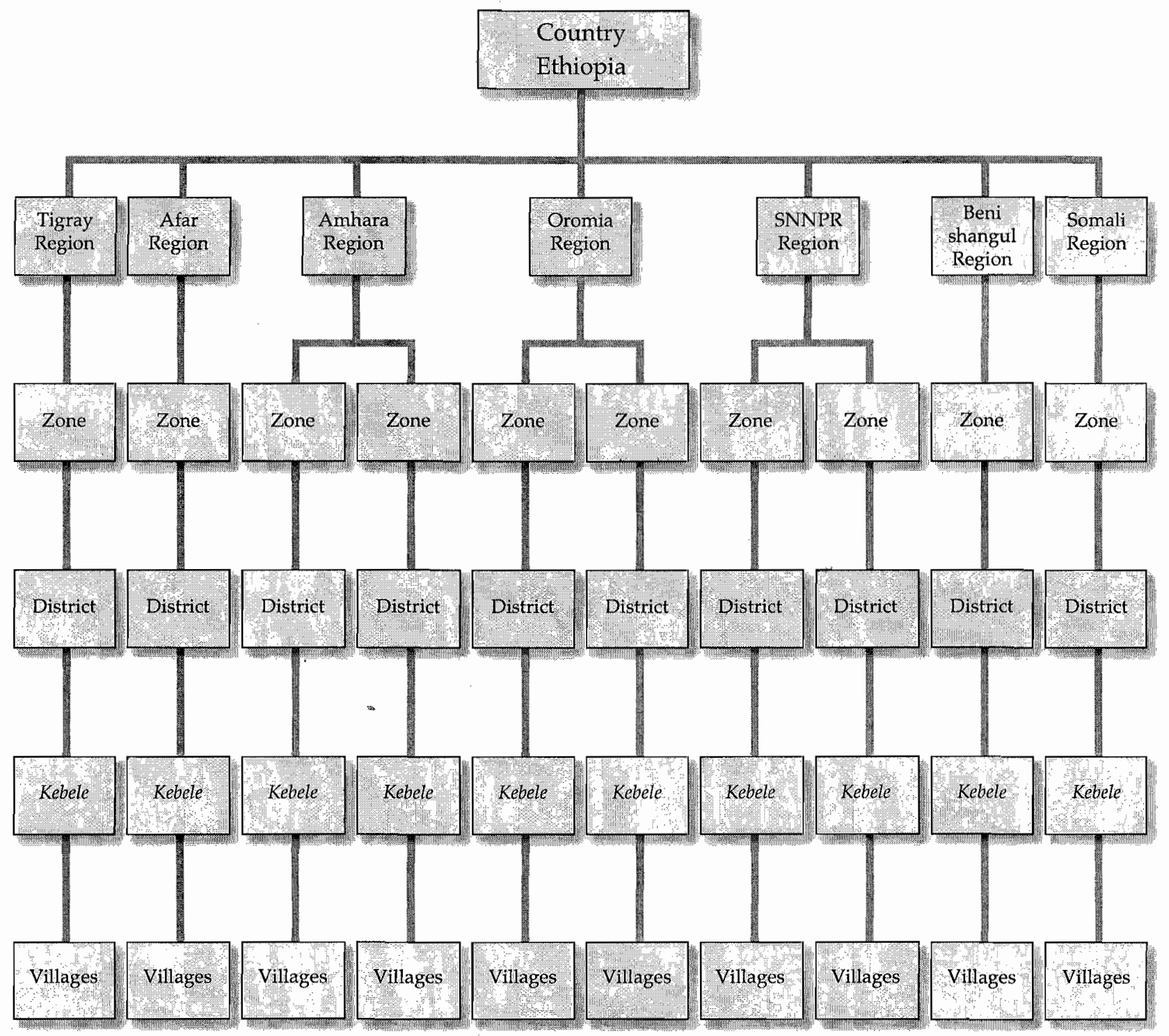


Sample size calculations were made with the assumption that incidence of fistula in sub-Saharan Africa is estimated to be $0.3 \%$ (unpublished hospital based report), average number of deliveries for a woman in Ethiopia is about 3.1 (6), average prevalence of fistula is about $0.93 \%, 95 \%$ confidence level and a worst acceptable frequency of $0.6 \%$. The calculated sample size was about 3,249 and it was multiplied by five to account for the multistage sampling amounting to 16,245 women. With a contingency of $10 \%$, about 18,000 women needed to be included in the study. This total sample size was distributed proportionally to the population size of the administrative regions.

Trained data collectors who spoke the local languages and completed secondary school administered the questionnaires to the study population. The activities of data collectors were guided and monitored by one or two supervisors for a zone and an overall coordinator who is a graduate in public health with rich experiences of community based research.

The questionnaires were translated into the different languages of the administrative regions and were pretested and modified in the way they best applied to the different cultures. Most coordinators and all supervisors being health workers checked identified cases for actual presence of obstetric fistula together with the respective health workers in the study areas or got them checked by health workers in the study areas.

The qualitative component consisted of in-depth interviews with fistula patients. Guide questions for in-depth interview were prepared on development of fistula and its consequences and women's life history. Thirty six in-depth interviews (27 with untreated and seven with treated patients) were conducted in four of the biggest administrative regions (Amhara, Oromia, SNNPR and Tigray). With the consent of the respondents, the interviews were tape-recorded. The records were then transcribed and translated to English, coded and thematic analysis conducted.

Ethical clearance was obtained from the National Ethical Clearance Committee and written informed consent was obtained from all fistula patients. Identified fistula patients were advised on how and where they could obtain help and they would be provided with transportation fee to the nearest functional fistula centre. As a result of this, at least twenty patients were able to have obstetric fistulae repaired at AAFH. Data were entered and analysed using SPSS version XI statistical package where prevalence of obstetic fistula and percentage distributions on characteristics of women with fistula were computed and comparisons made between treated and untreated fistula patients.

\section{RESULTS}

Socio-demographic characteristics: A total of 19,153 houses were visited with 97,765 inhabitants amounting to an average of 5.1 persons per household. Of these 49,589 (50.7\%) were males and $48,176(49.3 \%)$ were females. Women aged 15 years and above were $27,090(27.7 \%)$ and those between $15-49$ years were $22,826(23.3 \%)$. Forty one untreated and 14 treated fistula patients were identified in this study. Two women after having been identified as untreated fistula patients did not want to participate in the study. Likewise one treated woman refused to participate.

Twenty five untreated and four treated patients was reported from the Amhara administrative region. No cases were reported from the Somali region.

Among untreated patients eighteen women were married and 19 divorced. The median age at first marriage was 15 years. Twenty eight women were unable to read and write while the remaining eleven were literate.

Among treated patients, five women were married and eight divorced. The median age at marriage was 14 years. Nine women could not read and write and four reported to be literate.

Occurrence of fistula: The prevalence of obstetric fistula in this study population was 2 per 1,000 among women aged 15 years and above. Among untreated patients the prevalence would be 1.5 per 1,000 women. Overall prevalence of obstetric fistula among women of reproductive age groups (15-49 years) was estimated at 2.2 per 1,000 women.

The median age at occurrence of fistula for untreated patients was 22 years and ranged from 14 to 42 years. One woman was said to have had fistula at 14 years. For treated patients it was 18 years and ranged from 15 to 44 years. The median duration of fistula was eight years for untreated patients (mean $10 \pm 8.9$ years). 
Figure 1

Distribution of fistula patients by parity

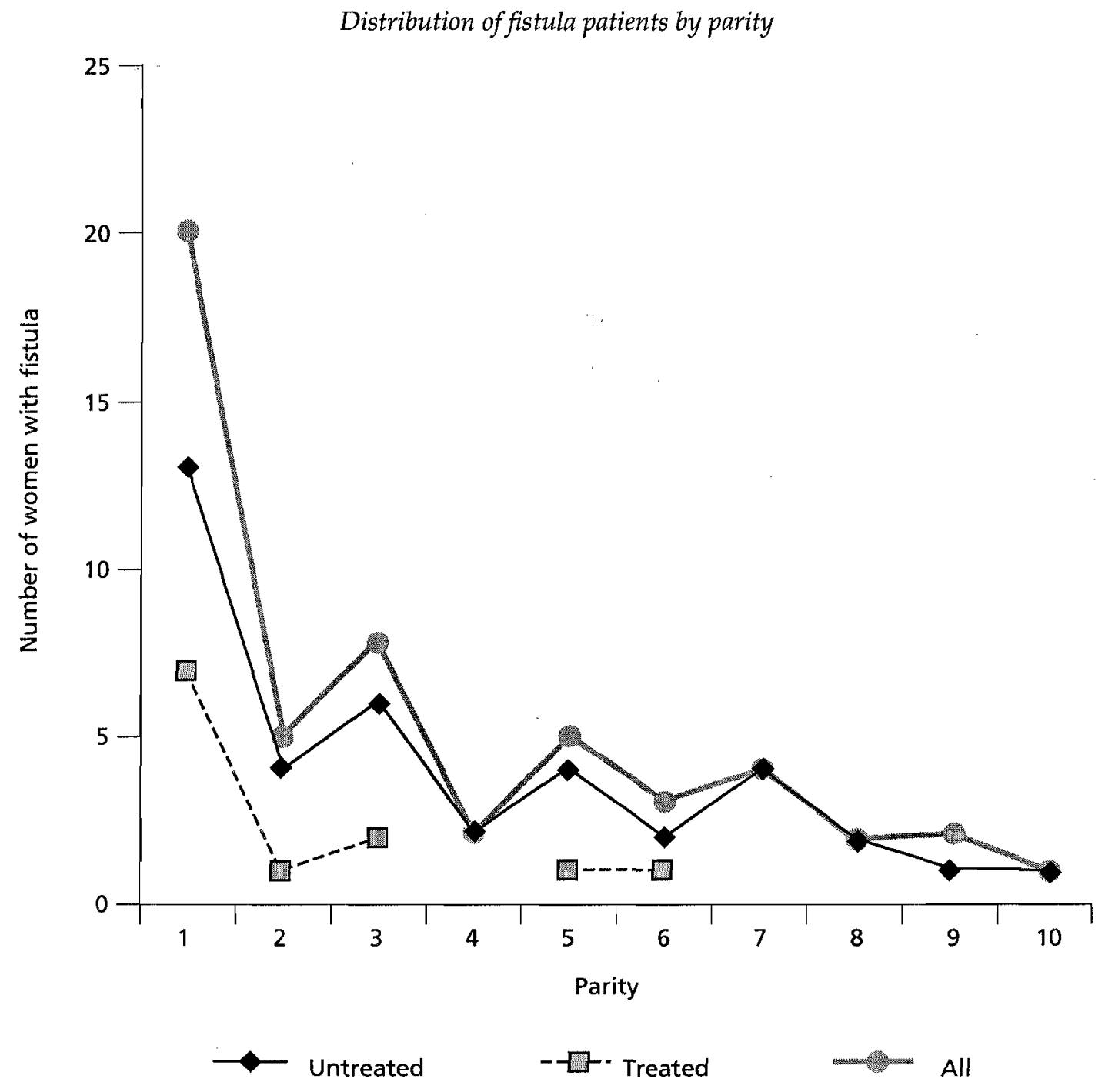

The highest number of obstetric fistulae in both treated (7/14) and untreated patients (13/39) occurred during the first delivery and about three fifth had occurred by the third delivery. However, obstetric fistulae also occurred at parities of 11 and 12 (Figure 1).

The most common type of fistula, in 34 untreated patients, was vesico-vaginal fistula, where patients stated that they could control faeces but not urine.

All respondents reported duration of labour of one day or more. The median number of days in labour was three and ranged from one day ( 24 hours) to eight days. The first and third quartiles were two and four days respectively.

A higher proportion of treated fistula patients delivered in health institutions compared to untreated patients ( $\mathrm{OR}=4.79,95 \% \mathrm{CI}=0.99,30.08$ ). Health service utilisation: Of the 39 untreated fistula patients, 21 delivered at home while the rest 16 delivered in health institutions. One woman delivered while travelling to a health institution. Among treated patients three delivered at home while ten delivered in health institutions.

Among the untreated fistula patients 18 visited health institutions for difficult labour whereas the rest 21 did not visit health institutions. Two women who reported to have visited health institutions for difficult labour did not deliver in health institutions. The minimum time that patients visited health institutions after labour started was 12 hours and the maximum was reported to be 144 hours (six days). Median and mode number of hours of visit after labor started was 72 hours (three days). Median travel time on foot, on horseback or by bus to the nearest health facility was three, four, two and a half hours respectively and ranged from one to 41 hours. 
Table 1

Socio-demographic characteristics of fistula patients in rural Ethiopia

\begin{tabular}{|c|c|c|c|}
\hline Characteristic & Untreated & Treated & Total \\
\hline \multicolumn{4}{|l|}{ Age (years) } \\
\hline $15-24$ & 8 & 5 & 13 \\
\hline $25-34$ & 8 & 3 & 11 \\
\hline $35-44$ & 20 & 2 & 22 \\
\hline $45-61$ & 5 & 4 & 9 \\
\hline \multicolumn{4}{|l|}{ Marital status } \\
\hline Married & 18 & 5 & 23 \\
\hline Divorced & 19 & 8 & 27 \\
\hline Widowed & 2 & - & 2 \\
\hline Missing & 2 & 1 & 3 \\
\hline \multicolumn{4}{|l|}{ Religion } \\
\hline Orthodox Christian & 27 & 7 & 34 \\
\hline Protestant & 9 & - & 9 \\
\hline Muslim & 3 & 6 & 9 \\
\hline Missing & 2 & 1 & 3 \\
\hline \multicolumn{4}{|l|}{ Literacy status } \\
\hline Iliterate & 28 & 9 & 37 \\
\hline Literate & 11 & 4 & 15 \\
\hline \multicolumn{4}{|l|}{ Ethnicity } \\
\hline Amhara & 26 & 6 & 32 \\
\hline Gedio & 7 & - & 7 \\
\hline Oromo & 4 & 2 & 6 \\
\hline Afar & 1 & 1 & 2 \\
\hline Amaro & 1 & & 1 \\
\hline Menge & - & 2 & 2 \\
\hline Tigrie & - & 2 & 2 \\
\hline \multicolumn{4}{|c|}{ Age at first marriage (years) } \\
\hline $6-14$ & 10 & 9 & 19 \\
\hline $15-17$ & 23 & 3 & 26 \\
\hline $18-22$ & 6 & 1 & 7 \\
\hline
\end{tabular}


Table 2

Age at occurrence of fistula in rural Ethiopia

\begin{tabular}{cccc}
\hline & Untreated & Treated & AII \\
\hline Age (years) & & & \\
$14-19$ & 11 & 7 & 18 \\
$20-29$ & 16 & 3 & 19 \\
$30-45$ & 12 & 3 & 15 \\
\hline All & 39 & 13 & 52 \\
\hline
\end{tabular}

Among the treated patients one visited a health institution for difficult/prolonged labour after 12 hours and two women each after 36 and 48 hours. Another was reported to have visited a health institution after 192 hours (eight days). Median travel time on foot or on horseback to the nearest health facility was three and two and half hours respectively and ranged from one to 48 hours.

The most frequently cited reason for not visiting health institutions was health service inaccessibility (distance) (10 out of 22) followed by shortage of money $(4 / 12)$. In three cases the women and/or families answered that they thought everything would be alright after a while without such grave consequences. In another three cases the women or family preferred home delivery by a traditional birth attendant. Two women responded that there was nobody to take them to health institutions.

Nine untreated fistula patients were referred to another health institution for difficult or prolonged labour out of which seven went to the referral institution and two did not go because of lack of money.

Fifteen untreated fistula patients had visited health institutions for the fistula problem while the rest 24 had not visited health facilities for this problem. Of those who visited health institutions for the fistula problem, ten were further referred to another hospital of which only two went to the referred hospital. The most common reason (ten women) for not going to the referred hospital was shortage of money.

Qualitative study findings of the perceived causes and conditions for the development of fistula: Obstetric fistula was mostly attributed to God's curse, somebody's fate or due to evil spirits. Marriage took place very early in life and there were different types of marriage arrangements. Family arrangement was the main type of marriage followed by abduction. Most respondents had horrible experience about marriage and the first sexual encounter. This was expressed by one of the respondents as "The sexual encounter was horrible, I hated him (the husband), I lost consciousness. On the first sex, people told me that there was massive bleeding with clots of blood and my flesh. I regained my consciousness after three days in my parents place." Those that visited health institutions acknowledged the advantage of having supportive husband and family. Those not treated mentioned poverty, lack of knowledge and lack of supportive husband as a reason for failing to seek care. Some also could not find a person who would accompany them to health institutions. An untreated patient explained why she was not treated by saying "I could not visit health institutions. Earlier my husband had taken me to the nearby health centre, but we couldn't make progress because of our poverty. My husband died three years ago and I could not even attempt to go for treatment since then."

One of the respondents described the delay in seeking care and the consequences as follows" The labour lasted for five days. Then I was taken to a private practitioner, where I paid 200 birr (USD 23.50). He asked for more (400 birr' $=$ USD 47). Finally he referred us and then they took me to Dembecha (small town with health centre) and Debre Markos (zone capital with a hospital). I don't remember how I went there, I was almost dead." Most of them had to be carried by neighbours and had to travel long distances to reach the first level health facility. As in the above case a second referral was common. This made the 
delay longer. Most had to get "free paper" from their kebeles. (smallest administrative unites) or woreda (district) administrative offices. The process is very time taking and getting the so called "free paper" maybe expensive. The following description of the situation was made by one of the patients "The labour became prolonged and one was taken to the nearby health institution. The health professional referred me to "Feres Bet" health centre. I was then referred to Debre Markos, I had to take free paper and I delivered on the way to Debre Markos. I had finished all my money and had nothing left for further treatment".

The actions taken when labour was prolonged included traditional practices such as rubbing the abdomen using butter, saying prayers, and then taking to health facility. Decisions to visit health institutions were usually made by husbands and family members. Most were taken to health facilities after the family had tried other options like traditional practices and local drug shops.

\section{DISCUSSION}

This study is the first community based study that has attempted to find out the magnitude of fistula and the factors associated with it in rural Ethiopia. Because of stigma and related problems, it was anticipated that not all fistula patients might be identified or some would leave their usual place of residence. To minimise this problem, the advantages of being involved in the study including free transport and treatment were explained to the community. Efforts were also made to approach community leaders to identify fistula patients in the community and disseminate information about the advantages of the study for the individual and the family/community.

Obstetric fistula prevalence was estimated at $0.2 \%$ in women aged 15 years and above. The estimate of fistula prevalence $(0.93 \%)$ entertained at the beginning of the study, based on hospital data appears too high. On the other hand a survey estimated prevalence of $0.17 \%$ among married women in Bangladesh (8).

All fistula patients had labour of more than one day duration and duration of up to eight days was reported. Obstructed labour is the main cause of obstetric fistula as was also reported by other studies (9-11).
Home delivery was more common in untreated fistula patients compared to the treated ones. In addition, a high proportion of untreated fistula patients $(21 / 39)$ did not visit health institutions at all for difficult or prolonged labour and the time elapsed before visiting health institutions was much higher for untreated patients compared to treated patients. This shows that more favourable conditions existed to seek health services by those who finally got treated when fistula developed. The most common reason for not visiting health institutions when labour was prolonged was inaccessibility of health services (distance) followed by shortage of money implying that making the services available and poverty alleviation are important factors in the reduction of obstetric fistula and its consequences. Other responses included lack of information and preference of home delivery. Thus, information about the services and improvement in the services so that women and families may choose to deliver at health institutions (where home deliveries may not be safe) are important points to consider in the improvement of quality of reproductive health services.

Most untreated patients (24/39) did not visit health institutions for fistula problems. On the other hand, among those who visited health institutions, most did not go to the referral health institutions, the main reason being shortage of money. This fact strengthens the role of poverty as the major constraint for treatment of fistula when high-level care is not near.

The median duration of fistula for untreated patients was eight years. This indicates that there are many fistula patients in the community that did not have the benefit of services for a long time, in spite of the fact that fistula repair services have been in the county for several decades.

The majority of the patients $(29 / 55)$ were divorced. Some studies have cited a similar divorce rate (3). Out of the 55 identified treated and untreated patients 37 were illiterate. This is in line with the distribution of literacy status in rural Ethiopia, where more than $65 \%$ of the women are illiterate (12). Illiteracy can also predispose to such grave problems because of its effects on lack of information, the capacity to have a gainful income and decision-making.

The difference in prevalence of obstetric fistula among regions is difficult to fully explain. It is possible that there are differences in underlying 
factors among administrative regions and ethnic groups. For example, the median age at first marriage (14 years) in the Amhara region was the lowest according to the Ethiopian Demographic and Health Survey (6). It may also be related to the differences in the mobility patterns of fistula patients from rural to urban areas. Moreover, underreporting may be more common in some regions compared to others. It is highly unlikely that there are no fistula cases in the Somali region because of the reasons mentioned above and the mobile nature of the population. Thus estimates of administrative regions should be interpreted with caution as these are influenced by the randomly selected area and the relatively small number of study population, particularly in the small regions is bound to give a less precise estimate while the estimate for the country as a whole would be more accurate.

In this study, obstetric fistula could occur at a young age of 14 years and it frequently took place during the first deliveries, although it was also observed at very high parities of 11 and 12 . Young age and first delivery have been associated with development of fistula in many studies (10-14). Young age and first delivery are predisposing factors to the development of fistula due to the undeveloped pelvis and obstructed labour. Among older women and the grand multipara, the reason for developing obstetric fistula could be prolonged labour due to abnormal presentation and foetal position with possible injury to the bladder and uterus.

The prevalence of untreated obstetric fistula in rural Ethiopia is about 1.5 per 1,000 women aged 15 years and above. Current Ethiopian Population is estimated at 77,000,000 (extrapolated from previous years' estimates, $\mathrm{MOH} 2004)$. The rural population is about $66,220,000$. Of this women aged 15 years and above would be $17,879,400$. Thus estimated number of untreated fistula patients in rural Ethiopia will be about 26,819 .

In summary obstetric fistula in rural Ethiopia affects women married at young age and who deliver for the first time to a large extent, although to a lesser extent fistula can occur in all age groups and parities. Marriage among fistula patients was usually arranged by families or conducted by abduction at young age. Access to health institutions and shortage of money were the most important problems for delays in visiting health institutions for prolonged labour and treatment of fistula. However, lack of knowledge about the cause of the problem, where to get appropriate service and attitude towards the health services also contribute to the development of fistula and lack of treatment. Thus, promotive, and preventive measures and identification and treatment of patients need to be intensified. Basic and emergency obstetric services should be brought closer to the community. Curving the situation in the long run requires economic improvement and improvement in the status of women.

\section{ACKNOWLEDGEMENTS}

This study was financially supported by the Fistula Foundation in America for which we are very grateful. We acknowledge the dedicated work of the field coordinators, supervisors, enumerators and data entry clerks. We appreciate the Federal Ministry of Health, health workers and health managers in the selected areas who have contributed a lot to the success of this study.

The Addis Ababa Fistula Hospital administrative staff have done a great job in facilitating this research. Special thanks go to $\mathrm{Mr}$ Abebe Gesit, AAFH administrator. Lastly, we extend our deepest gratitude to community members of the study areas, particularly treated and untreated fistula patients who participated in the study.

\section{REFERENCES}

1. WHO Department of Making Pregnancy Safer. Obstetric Fistula. Guiding principles for clinical management and programme development. 2006: 11-30, Geneva.

2. Wall L.L. Dead mothers and injured wives: The social context of maternal morbidity and mortality among the Hausa of Northern Nigeria. Stud. Fam. Plann. 1998; 29: 341-359.

3. Kelly J. and Kwast B.E. Epidemiological study of vesicovaginal fistulas in Ethiopia. Int. Urogynaecol. J. 1993; 4: 278-281.

4. Liskin L.S. Maternal morbidity in developing countries: A review and comments. Int. J. Obstet. Gynecol. 1992; 37: 77-87.

5. Muleta M. Obstetric Fistula: A retrospective study of 1210 cases at the Addis Ababa Fistula Hospital. Obstet. Gynaecol. 1997; 17: 68-70. 
6. Central Statistics Agency and ORG Macro International Ethiopian Demographic and health survey, 2000. Addis Ababa and Cleveland. 2001.

7. Ministry of health of Federal Democratic Republic of Ethiopia. Health and Health related indicators. Planning and Programming Department, Ministry of Health. Addis Ababa. 2003.

8. Waiz N.K. et al. Situational analysis of obstetric fistula in Bangladesh (Unpublished document). 2003.

9. Tahzib F. Epidemiological determinants of vesicovaginal fistulas. Brit. J. Obstet. Gynaecol. 1983; 90: 387391.

10. Ampofo E.K., Omotara B.A., Out T. and Uchebo G. Risk factors of vesico-vaginal fistula in Maiduguri,
Nigeria: A case control study. Trop. Doct. 1990; 20: 138-139.

11. Wall L.L., Karshima J.A., Kirschner C. and Arrowsmith S.D. The obstetric vesico-vaginal fistula: characteristics of 899 patients fromJos, Nigeria. Amer. J. Obstet. Gynecol. 2004; 190: 1011-1019.

12. UNICEF. The State of the World's Children, http:// www.unicef.org 2006.

13. Ibrahim T., Sadiq A.U. and Daniel S.O. Characteristics of WF patients as seen at the specialist hospital in Sokoto, Nigeria. West Afr. J. Med. 2000; 19: 59-63.

14. Ljiya M.A. and Aboyeji P.A. Obstetric urogenital fistula: The Ilorin experience, Nigeria. West Afr. J. Med. 2004; 23: 7-9. 